\title{
Frontotemporal dementia and amyotrophic lateral sclerosis-associated disease protein TDP-43 promotes dendritic branching
}

\author{
Yubing Lu, Jacob Ferris and Fen-Biao Gao*
}

Address: Gladstone Institute of Neurological Disease, and Department of Neurology, University of California, San Francisco, CA 94158 USA

Email: Yubing Lu - ylu@gladstone.ucsf.edu; Jacob Ferris - jfferis@gladstone.ucsf.edu; Fen-Biao Gao* - fgao@gladstone.ucsf.edu

* Corresponding author

Published: 25 September 2009

Molecular Brain 2009, 2:30 doi:10.1 186/1756-6606-2-30

This article is available from: http://www.molecularbrain.com/content/2/I/30

(c) 2009 Lu et al; licensee BioMed Central Ltd.

This is an Open Access article distributed under the terms of the Creative Commons Attribution License (http://creativecommons.org/licenses/by/2.0), which permits unrestricted use, distribution, and reproduction in any medium, provided the original work is properly cited.
Received: II September 2009

Accepted: 25 September 2009

\begin{abstract}
Background: TDP-43 is an evolutionarily conserved RNA-binding protein implicated in the pathogenesis of frontotemporal dementia (FTD), sporadic and familial amyotrophic lateral sclerosis (ALS), and possibly other neurodegenerative diseases. In diseased neurons, TDP-43 is depleted in the nucleus, suggesting a loss-of-function pathogenic mechanism. However, the normal function of TDP-43 in postmitotic neurons is largely unknown.
\end{abstract}

Results: Here we demonstrate that overexpression of Drosophila TDP-43 (dTDP-43) in vivo significantly increases dendritic branching of sensory neurons in Drosophila larvae. Loss of dTDP-43 function, either in a genetic null mutant or through RNAi knockdown, decreased dendritic branching. Further genetic analysis demonstrated a cell-autonomous role for ITDP-43 in dendrite formation. Moreover, human TDP-43 (hTDP-43) promoted dendritic branching in Drosophila neurons, and this function was attenuated by mutations associated with ALS.

Conclusion: These findings reveal an essential role for TDP-43 in dendritic structural integrity, supporting the notion that loss of normal TDP-43 function in diseased neurons may compromise neuronal connectivity before neuronal cell loss in FTD and ALS.

\section{Background}

Frontotemporal lobar degeneration (FTLD) is a devastating age-dependent neurodegenerative condition primarily associated with impairments in cognition and social behaviors, as well as personality changes and other clinical abnormalities [1]. Frontotemporal dementia (FTD), a major clinical syndrome of FTLD, is now recognized as the most common form of early-onset age-dependent dementia before the age of 60 [2]. Increasing clinical, pathological, and molecular evidence indicates that FTD and amyotrophic lateral sclerosis (ALS) are closely related conditions [3].
In addition to pathogenic mutations in the microtubule binding protein tau $[4,5]$, rare mutations in other genes also cause FTD, such as those encoding valosin-containing protein, an AAA-type ATPase associated primarily with the endoplasmic reticulum [6], and CHMP2B, a component of the endosomal sorting complex required for transport III [7]. Mutations in progranulin located on chromosome 17 also cause FTD in some patients without tau pathology $[8,9]$. Progranulin is a secreted molecule, and many pathogenic mutations lead to progranulin haploinsufficiency. The pathogenic mechanism of FTD caused by progranulin deficiency is not known, but one of 
the pathological hallmarks is tau-negative and ubiquitinpositive neuronal inclusions that contain TDP-43 and its fragments [10-13]. Genetic mutations in TDP-43 are responsible for some sporadic and familial amyotrophic lateral sclerosis (ALS) [14-16], further reinforcing the notion that FTD and ALS are closely related conditions, referred to as TDP-43 proteinopathies [17]. In healthy cells, TDP-43 mostly resides in the nucleus. In diseased neurons, however, TDP-43 is excluded from the nucleus and aggregates in the cytosol [10]. Moreover, in axotomized motor neurons, TDP-43 expression is dramatically increased and becomes prominently localized in the cytosol [18]. These findings raise the possibility that loss of the normal function of TDP-43, especially in the nucleus, contributes to the initiation or progression of disease.

TDP-43 is a ubiquitously expressed RNA-binding protein that contains two RNA recognition motifs, a glycine-rich region, a nuclear localization signal, and a nuclear export signal [19]. It is not known which aspects of cellular physiology are regulated by TDP-43. TDP-43 is primarily localized in the nucleus at the active sites of transcription and cotranscriptional splicing in mammalian neurons [20]. Indeed, limited experimental evidence indicates that TDP43 is involved in transcription [21] and splicing [22,23] and possibly in mRNA transport and local translation as well [24]. TDP-43 and many other proteins form a large complex with Drosha [25], but its possible involvement in the microRNA pathway remains to be further explored. To understand how TDP-43 contributes to the pathogenesis of FTD and ALS, it is essential to dissect its normal functions in postmitotic neurons.

TDP-43 is highly conserved at the amino acid level from flies to humans, suggesting an evolutionarily conserved function $[19,23,26]$. To investigate the normal roles of TDP-43 in postmitotic neurons, we used dendrites of sensory neurons in the Drosophila peripheral nervous system (PNS) as our assay system and performed both gain- and loss-of-function genetic studies. We also examined the functional significance of some genetic mutations in TDP43 that are associated with ALS. Our findings support the notion that a TDP-43 loss-of-function mechanism may contribute to the pathogenesis of FTD and ALS.

\section{Methods}

\section{Fly strains and genetics}

All flies were raised on standard food medium and kept at $25^{\circ} \mathrm{C}$. dTDP-43 RNAi lines 38377 and 38379 were obtained from the Vienna Drosophila RNAi Center (VDRC). The $d T D P-43 Q 367 X$ mutant allele was identified from the Seattle Drosophila TILLING Project (Fly-TILL, Fred Hutchinson Cancer Research Center) using specific tilling primers (Additional file 1). dTDP-43Q367X/CyO, GFP flies were crossed with Pin/CyO, GFP; Gal4221, UAS- $m C D 8$-GFP to establish the stock $d T D P-43 Q 367 X / C y O$, GFP; Gal4221, UAS-mCD8-GFP/+. The Gal4221 driver was used to label ddaE and ddaF neurons with mCD8-GFP and drive the expression of transgenes [27]. To visualize dendritic phenotypes of $\mathrm{ddaE}$ and $\mathrm{ddaF}$ neurons in third instar larvae, we crossed dTDP-43Q367X/CyO, GFP; Gal4221, UAS- $m C D 8-G F P /+$ flies with $d T D P-43 \mathrm{Q} 367 \mathrm{X} / \mathrm{C} \gamma \mathrm{O}$, GFP or $w^{1118}$ flies to generate dTDP-43Q367X/dTDP-43Q367X; Gal4221, UAS-mCD8-GFP/+ or dTDP-43Q367X/+; Gal4221, UAS- $m C D 8-G F P /+$ third instar larvae. For RNAi expression, dTDP-43Q367X/CyO, GFP; Gal4221, UAS-mCD8-GFP/+ flies were crossed with UAS- $d T D P-43$ RNAi lines (VDRC 38377 and 38379) to generate dTDP-43Q367X/+; Gal4221, UAS-mCD8-GFP/38377, and dTDP-43Q367X/38379; Gal4221, UAS- $m C D 8-G F P /+$ third instar larvae for phenotypic analysis. For transgene overexpression, Gal4221, UAS-mCD8-GFP flies were crossed with UAS- $\mathrm{ATDP}-43$, UAS-hTDP-43, UAS-hTDP-43-M337V, or UAS-hTDP-43Q331K transgenic lines. In the above experiments, Gal4221, UAS-mCD8-GFP/+ third larvae served as the control.

\section{Generation of transgenic Drosophila lines}

Full-length $h T D P-43$ cDNA was cloned from HEK293 cells (provided by Dr. J.-A. Lee). To generate UAS-hTDP-43, UAS-hTDP-43-M337V, UAS-hTDP-43-Q331K, and UAShTDP-43-C-terminal fragment (amino acids 209-414) constructs, the corresponding primers (Additional file 1) were used to amplify DNA fragments, which were then cloned into the pUAST vector. To generate UAS-dTDP-43 constructs, the full-length dTDP-43 coding sequence was amplified from the cDNA plasmid GH09868 (Drosophila Genomics Resource Center) and cloned into the pUAST vector. These constructs were confirmed by sequencing and microinjected into wild-type $\left(w^{1118}\right)$ embryos to generate transgenic lines.

\section{Antibody production and western blot}

Anti-dTDP-43 polyclonal antibody was generated by immunizing rabbits with a peptide fragment spanning amino acids 179-192 (Thermo Fisher Scientific). For protein expression analysis, adult flies were frozen in ethanol with dry ice and vortexed to remove heads. Approximately 30 heads from each genotype were homogenized in $50 \mu \mathrm{l}$ of lysis buffer $(0.137 \mathrm{M} \mathrm{NaCl}, 20 \mathrm{mM}$ Tris, $\mathrm{pH}$ 8.0, 10\% glycerol, $1 \%$ NP- $40,0.1 \%$ SDS, $0.1 \%$ sodium deoxycholate, $1 \mathrm{mM}$ DTT, Pierce protease inhibitors and phosphatase inhibitors). Homogenate was heated at $65^{\circ} \mathrm{C}$ for $10 \mathrm{~min}$ and centrifuged at $4^{\circ} \mathrm{C}$ for $10 \mathrm{~min}$ at $13,000 \mathrm{rpm}$. Protein concentrations were determined using Bradford Assay (Bio-Rad).

Supernatant containing $10 \mu \mathrm{g}$ of protein was separated on a $10 \%$ acrylamide SDS gel and transferred to a PVDF membrane (Bio-Rad) in a wet transfer system at $4{ }^{\circ} \mathrm{C}$ for $60 \mathrm{~min}$ at $100 \mathrm{~V}$. The membrane was incubated in block- 
ing solution containing 5\% milk in TBST (25 mM Tris$\mathrm{HCl}, 137 \mathrm{mM} \mathrm{NaCl}, 3 \mathrm{mM} \mathrm{KCl}, \mathrm{pH} 7.4$, and $0.1 \%$ Tween20) at $4{ }^{\circ} \mathrm{C}$ overnight, with dTDP-43 antibody (1:1000 in blocking solution) at room temperature for $3 \mathrm{~h}$, and finally with anti-rabbit HRP-conjugated secondary antibody (Jackson Immunoresearch; 1:10,000) for $1 \mathrm{~h}$. The signal was visualized with chemiluminescent substrate (Supersignal West Pico, Pierce). For other western blot analyses, the primary antibodies were hTDP-43 antibody (1:1000; 10782-2-AP, Proteintech), and $\beta$-actin antibody (1:1500; Cell Signaling).

\section{Quantitative RT-PCR (qRT-PCR) analysis}

Total RNAs were extracted from adult heads with Trizol (Invitrogen) and used as templates to generate cDNAs with TaqMan reverse transcription reagent (Applied Biosystems). cDNAs were used as templates for qRT-PCR in a final volume of $25 \mu \mathrm{l}$. A standard curve was run in each PCR reaction. Individual values were normalized to the value of the gene encoding the ribosomal protein RP-49. Two pairs of primers were designed to detect dTDP-43 transcripts (Additional file 2). All reactions were performed three times. Relative mRNA expression was calculated using the standard curve method and the delta-delta Ct method.

\section{Mosaic analysis with a repressible cell marker (MARCM)} MARCM analysis of sensory neurons in the Drosophila PNS was performed as described [28]. First, the dTDP43 Q367X allele was recombined onto the chromosome containing FRTG13. FRTG13, dTDP-43Q367X/CyO or FRTG13/CyO male flies were crossed with Gal4C155, UAS-mCD8-GFP, hs-FLP1; FRT ${ }^{G 13}$, Gal80/CyO virgin females to generate Gal4C155, UAS-mCD8-GFP, hs-FLP1/+; FRTG13, Gal80/ FRTG13, dTDP-43Q367X and Gal4C155, UAS-mCD8-GFP, hsFLP1/+; FRTG13, Gal80/FRTG13 embryos, respectively. Embryos from these crosses were collected on grape agar plates for $3 \mathrm{~h}$ in a $25^{\circ} \mathrm{C}$ incubator. The embryos were aged for $3 \mathrm{~h}$ and heat-shocked in a $37^{\circ} \mathrm{C}$ water bath for $40 \mathrm{~min}$ to induce mitotic recombination. The embryos were then kept in a moisture chamber at $25^{\circ} \mathrm{C}$ for $3-4$ days. Third instar larvae were collected, and larvae that contained a single mCD8::GFP-labeled dorsal cluster PNS neuron were selected under a Nikon fluorescence dissection microscope. Images of the dendritic morphology of single DA neurons were recorded with a confocal microscope (Nikon, D-Eclipse C1). The significance of differences in dendritic branching complexity was determined with Student's $t$ test.

Quantitative Analysis of dendritic ends of sensory neurons The dendritic morphology of GFP-labeled dorsal sensory neurons was recorded with a confocal microscope (Nikon, D-Eclipse C1), and dendritic branches of ddaE or ddaF neurons in the A3 dorsal cluster were counted as described [28]. Briefly, dendritic ends of DA neuron images were identified visually and highlighted with dots, which were counted with Adobe Photoshop software. The data were analyzed by Student's $t$ test.

\section{Results \\ dTDP-43 promotes dendritic branching of sensory neurons in Drosophila}

To examine neuronal functions of dTDP-43, we generated multiple UAS-dTDP-43 transgenic fly lines with insertion sites on different chromosomes. Because dendritic branching patterns are critically important for neuronal function and connectivity and dendritic defects are associated with many neurological disorders [29,30], we focused our functional analysis of TDP-43 on dendrites. To do so, we used the sensory neurons in Drosophila larvae as our assay system, which has been useful in uncovering molecular mechanisms of dendritic morphogenesis [31]. To drive transgene expression, we used the neuronal subtype-specific driver Gal4221, which targets gene expression in two sensory neurons only in each hemisegment [27].

Ectopic expression of dTDP-43 markedly increased the number of small terminal dendritic branches (Figure 1B). For instance, the number of dendritic ends increased from $29.2 \pm 1.0(\mathrm{n}=14)$ to $51.2 \pm 3.0(\mathrm{n}=10)(P<0.001)$ in ddaE neurons, and from $22.8 \pm 1.0(\mathrm{n}=14)$ to $39.9 \pm 1.9$ $(\mathrm{n}=10)(P<0.001)$ in ddaF neurons (Figure $1 \mathrm{C})$. Interestingly, most of the small terminal dendritic branches caused by dTDP-43 expression were concentrated near the cell body of ddaE neurons (Figure 1B). This effect of dTDP-43 was confirmed in studies with other UAS- $d T D P$ 43 transgenic fly lines with different insertion sites on the second or third chromosomes (data not shown).

\section{dTDP-43 is required for normal viability of adult flies}

Next, we generated $d T D P-43$ loss-of-function mutant flies. We used the service from the Seattle Drosophila TILLING Project (Fred Hutchinson Cancer Research Center) and obtained several fly lines in which point mutations were found in $d T D P-43$. One, a nonsense mutation with a single nucleotide change from $\mathrm{G}$ to $\mathrm{A}$, introduced a stop codon at amino acid 367 (Figure 2A). This mutation was confirmed by sequencing PCR products amplified from the genomic DNA of $d T D P-43^{Q 367 X}$ heterozygous adult flies (Figure 2B). To confirm that this mutant allele is a protein-null allele, we raised a rabbit polyclonal antibody against the dTDP-43 peptide fragment spanning amino acids 179-192. On western blot, this antibody recognized a protein band with the predicted molecular weight of dTDP-43 in lysates from adult wildtype but not in $2 T D P$ 43Q367X mutant flies (Figure 2C). The intensity of this band was decreased by about half in $D f(2 R) 106 /+$ heterozygous flies (data not shown). Since this antibody did not detect the putative truncated dTDP-43 protein in mutant flies (Figure 2C), it is likely that the truncated dTDP-43 protein is unstable, in addition to the reduced abundance 
A

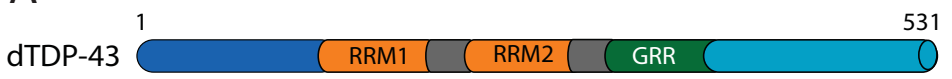

B
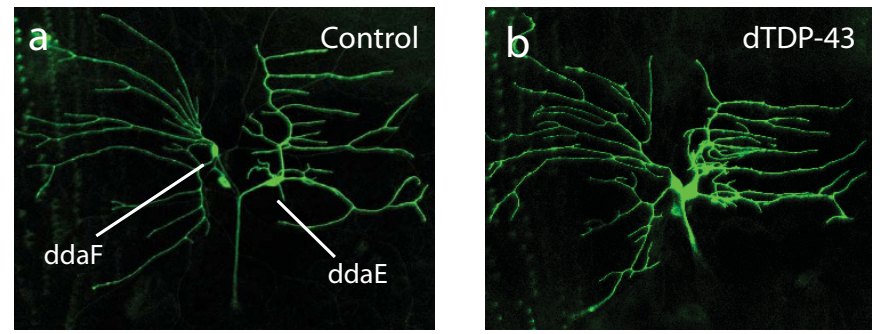

C

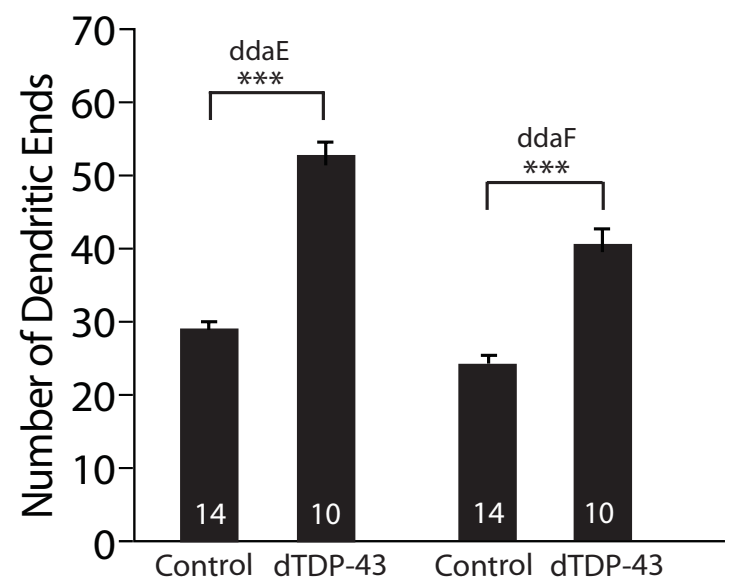

\section{Figure I}

dTDP-43 promotes dendritic branching in Drosophila. (A) Schematic representation of the domain structure of dTDP43. RRM: RNA recognition motif. GRR: glycine-rich region. (B) Dendritic phenotypes of ddaE and ddaF sensory neurons in the A3 segment of third instar larvae that are either wildtype (a) or overexpress dTDP-43 with the Gal422I driver (b). (C) Quantification of dendritic ends of $\mathrm{ddaE}$ and $\mathrm{ddaF}$ neurons. The number of neurons examined is indicated in each column. Values are mean \pm SEM. $* * * P<0.001$.

of the $d T D P-43$ mRNA containing the premature stop codon (Figure 2D). Thus, $d T D P-43$ Q367X is a protein null allele.

Homozygosity for $d T D P-43^{Q 367 X}$ was semi-lethal, with some mutant adult flies surviving to adulthood. For instance, the ratio of $d T D P-43 Q 367 X / C \gamma O$ to $d T D P-43 Q 367 X /$ $d T D P-43 Q 367 X$ progenies of $d T D P-43 Q 367 X / C y O$ flies was about 4-5:1, instead of the expected 2:1 ratio for nonlethal mutations. This finding is consistent with a recent report that $d T D P-43$ deletion mutations in were semi-lethal as well [26]. Expression of UAS-dTDP-43 RNAi (38377 or 38379 , VDRC) driven by tubulin-Gal4 resulted in a similar lethal phenotype. Overexpression of dTDP-43 with the pan-neuronal Gal4 ${ }^{\mathrm{C} 155}$ driver also led to a similar lethal phenotype, indicating that the proper level of dTDP-43 expression in the nervous system is required for normal viability. Indeed, ectopic expression of dTDP-43 in the eye caused a severe retinal degeneration phenotype (data not shown).

\section{Loss of dTDP-43 activity reduces dendritic branching}

To examine dendritic phenotypes caused by loss of dTDP43 activity, we first expressed mCD8-GFP under the control of Gal4221 in ddaE and ddaF neurons in wildtype or dTDP-43Q367X homozygous mutant third instar larvae. Compared with wildtype neurons (Figure 3A), loss of dTDP-43 function significantly decreased dendritic branching (Figure $3 \mathrm{~B}$ ). For instance, the number of dendritic ends of ddaE neurons in the A3 segment decreased from $31.4 \pm 1.0(\mathrm{n}=17)$ in wildtype larvae to $24.4 \pm 0.5$ $(\mathrm{n}=16)$ in $d T D P-43^{Q 367 X}$ homozygous mutant larvae $(P<$ 0.001 ) (Figure 3C). A similar decrease was observed in ddaF neurons (Figure 3D). 


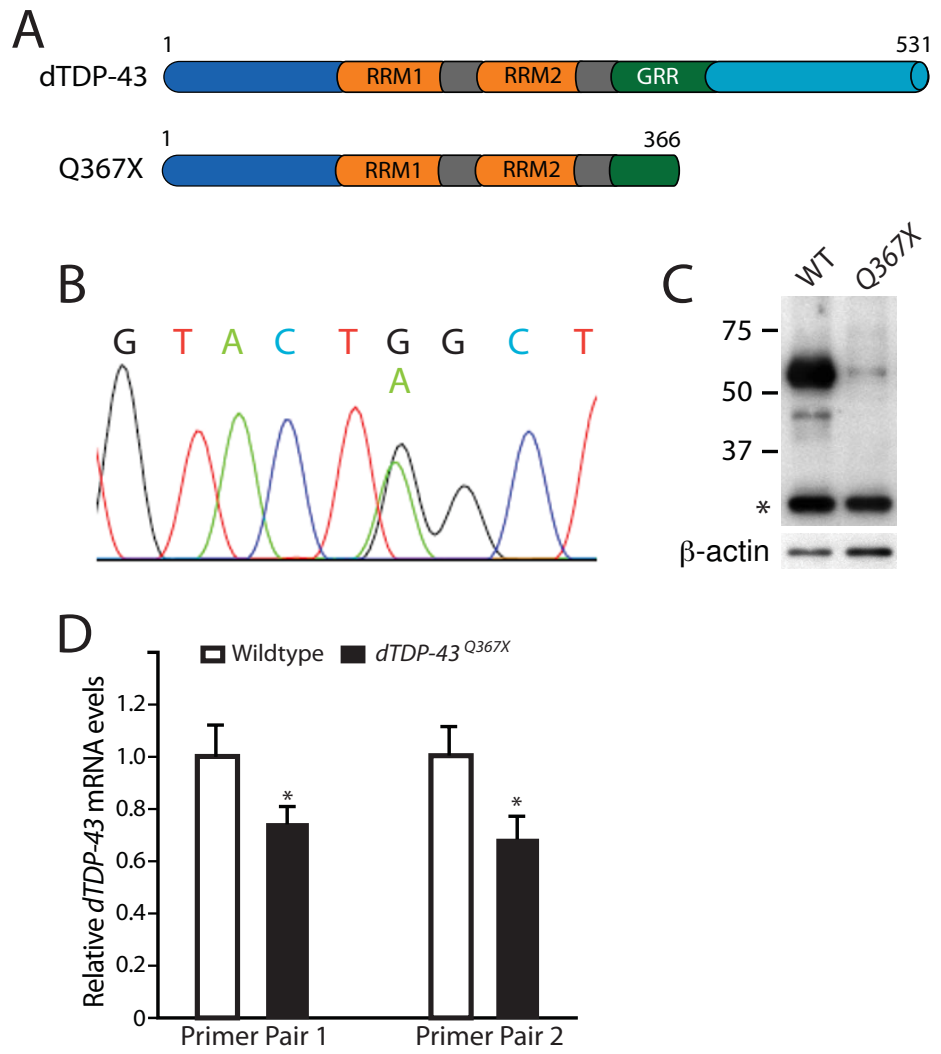

\section{Figure 2}

Generation of a dTDP-43 null allele. (A) Schematic representation of the truncated dTDP-43 protein caused by the single nonsense nucleotide mutation at amino acid 367. (B) Sequencing of the PCR fragment amplified from the genomic DNA of heterozygous flies confirmed the single nucleotide mutation from $G$ to $A$. (C) Western blot analysis of protein lysates from the heads of wildtype (WT) or DTDP-430367X homozygous mutant adult flies confirmed the absence of full-length dTDP-43 in mutants. The asterisk indicates a nonspecific band recognized by this antibody. The rabbit polyclonal antibody was raised against the peptide fragment spanning amino acids $179-192$ and did not recognize the putative truncated dTDP-43 in mutants, indicating instability of the mutant dTDP-43 mRNA or protein. (D) qRT-PCR analysis of dTDP-43 mRNA levels in wildtype and dTDP-43Q367X mutant flies. Two pairs of primers (Additional file 2 ) used for qRT-PCR yielded similar results. Values are mean \pm SD. $* P<0.05$.

Since ectopic overexpression of dTDP-43 markedly increased dendritic branching, it would be difficult to interpret results obtained by using the UAS-Gal4 system to rescue the dendritic phenotype in $d T D P-43$ Q367X mutants. Therefore, to further confirm that loss of dTDP43 activity reduces dendritic branching, we used two independent $d T D P-43$ RNAi lines obtained from VDRC to knock down dTDP-43 expression in these neurons. Again, the number of dendritic ends was decreased in ddaE (Figure 3C) and ddaF neurons (Figure 3D). These findings demonstrate that dTDP-43 has an essential role in patterning dendritic formation in vivo.

\section{dTDP-43 has a cell-autonomous function in dendritic branching}

In the RNAi experiment described above, dTDP-43 activity was knocked down in only a small number of sensory neurons, suggesting that dTDP-43 functions in a cellautonomous manner to control dendritic branching. To further confirm this possibility, we used the mosaic analysis with a repressible cell marker (MARCM) technique, which allows one to generate GFP-labeled single neurons containing a mutation of a gene of interest in a mostly wildtype Drosophila larva or adult [32]. Using this approach, we found that compared with wildtype ddaE neurons (Figure 4A), loss of dTDP-43 function specifically in ddaE neurons reduced dendritic branching (Figure 4B), consistent with the genetic analysis of these neurons in dTDP-43Q367X homozygous mutant larvae (Figure 3). dTDP-43Q367X mutant ddaE neurons in the A3 segment had fewer dendritic ends than wildtype neurons labeled by MARCM $(23.3 \pm 3.4(n=6)$ vs. $31.3 \pm 4.9(n=6)(P<$ $0.001)$. This result indicates that dTDP-43 functions in a cell-autonomous manner to regulate dendritic branching. 

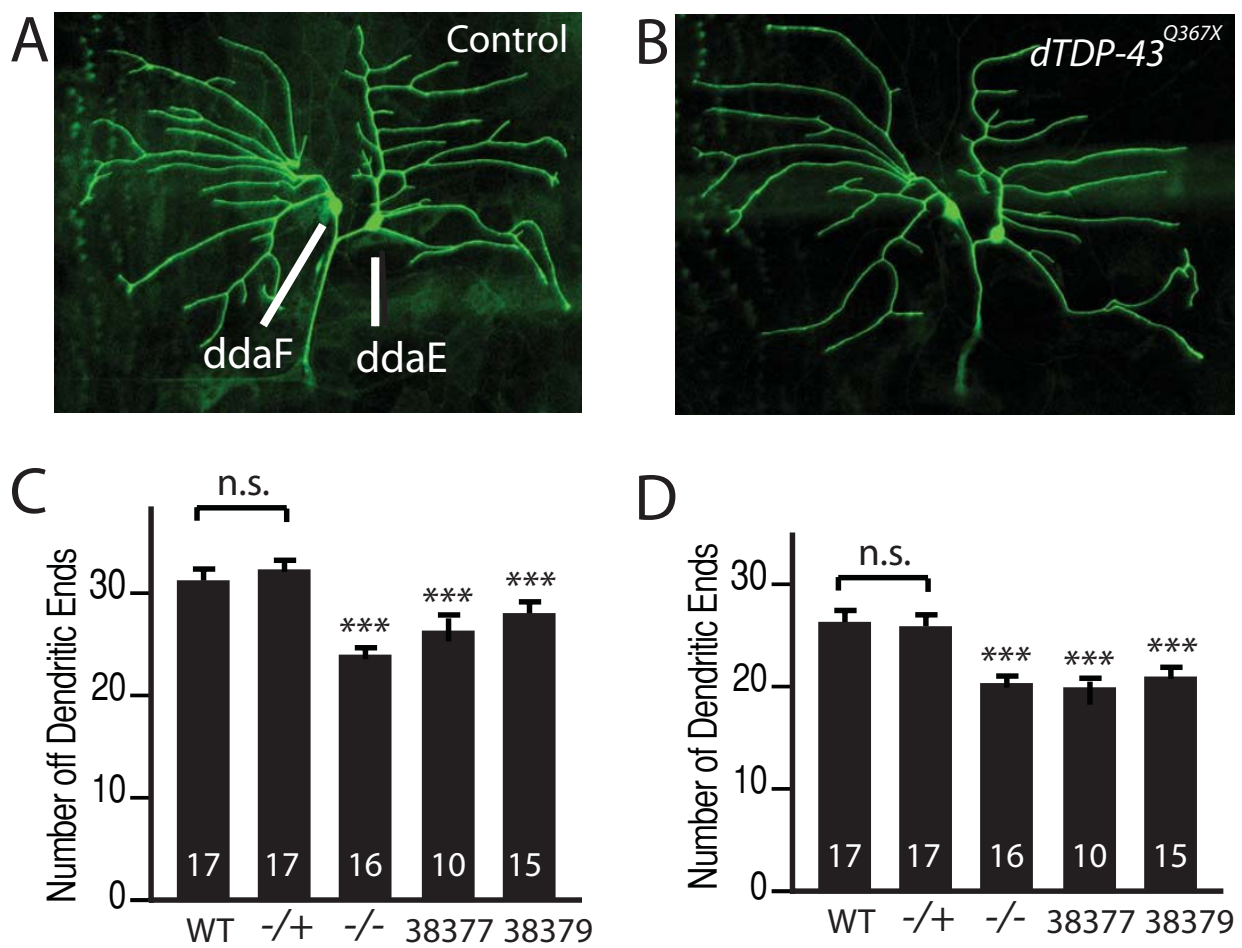

Figure 3

Loss of dTDP-43 activity led to decreased dendritic branching. (A) Dendritic branching pattern of ddaE and ddaF neurons in a wildtype larva. (B) ddaE and daF neurons in a dTDP-43Q367X homozygous mutant third instar larva. The neurons in A and B were labeled with mCD8-GFP under the control of Gal422I. (C) Quantification of dendritic ends of ddaE neurons. (D) Quantification of dendritic ends of ddaF neurons. The number of neurons examined is indicated in each column. Values are mean \pm SEM ***P $<0.00$ I. The effect of loss of dTDP-43 function on dendritic formation was confirmed by expressing two independent UAS-dTDP-43 RNAi constructs, 38377 and 38379, in ddaE and ddaF neurons in the dTDP-43Q367X/+ background.

hTDP-43 promotes dendritic branching in fly neurons and ALS-associated disease mutations attenuates this activity TDP-43 is an evolutionarily conserved protein whose amino acid sequence is highly homologous in flies and humans. To examine whether human TDP-43 (hTDP-43) also promotes dendritic branching, we generated multiple lines of UAS-hTDP-43 transgenic flies (Figure 5A). The Cterminal fragment of hTDP-43 and several point mutations have been implicated in the pathogenesis of FTD and ALS [10,14-17], but the mechanisms are unclear. To address this issue, we also generated multiple transgenic fly lines to express these mutant hTDP-43 proteins (Figure $5 \mathrm{~A})$. The level of transgene expression can vary depending on the insertion site in the genome. We therefore performed western blot analysis and selected individual transgenic fly lines that, when crossed with the GMR-Gal4 line, expressed hTDP-43WT and hTDP-43Q331K or hTDP$43^{\mathrm{M} 337 \mathrm{~V}}$ at comparable levels (Figure 5B).

Ectopic expression of hTDP-43 in Drosophila neurons also promoted dendritic branching (Figure 6). The number of dendritic ends for ddaE neurons was increased from 29.5 $\pm 0.8(\mathrm{n}=14)($ Figure $6 \mathrm{~A})$ to $55 \pm 1.6(\mathrm{n}=29)(P<0.001)$ (Figure 6B, E). A similar effect was observed for ddaF neurons (Figure 6B, F). The ectopic expression of the hTDP-43 C-terminal fragment did not affect dendrite branching (data not shown). As with dTDP-43, ectopic expression of hTDP-43 increased in dendritic ends mostly near the cell body (Figure 6B). These findings suggest that hTDP-43 and dTDP-43 are functionally conserved and likely exert their effects on dendritic branching through the same genetic pathways.

Both of those ALS-associated mutant proteins promoted dendritic branching to a much lesser extent than wildtype hTDP-43 (Figure 6C). ddaE neurons expressing hTDP$43^{\text {WT }}$ had $55 \pm 1.6(n=29)$ dendritic ends but the neurons expressing hTDP-43M337V or hTDP-43Q331K had only 41.1 $\pm 1.5(\mathrm{n}=18)$ or $44.3 \pm 2.0(\mathrm{n}=21)$ dendritic ends, respectively $(P<0.001)$ (Figure 6E). A similar effect was observed for ddaF neurons (Figure 6F). Thus, ALS-associated mutations in hTDP-43 attenuated its dendrite-pro- 

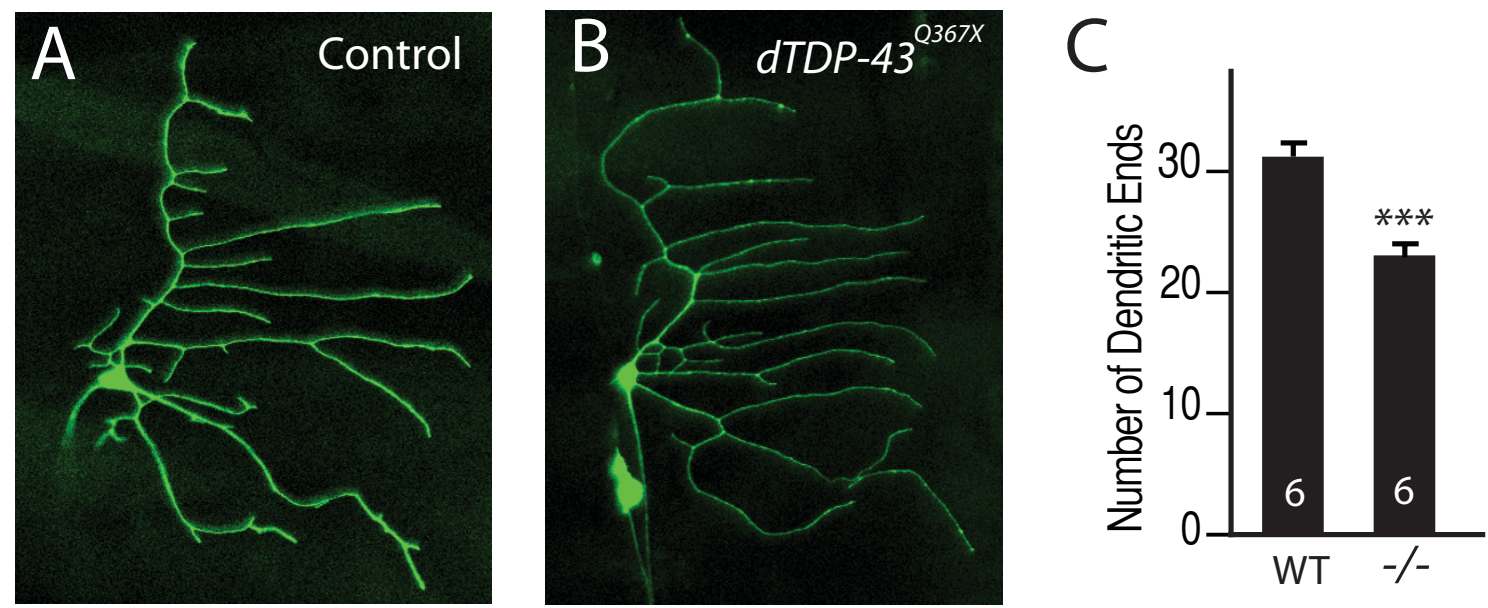

\section{Figure 4}

MARCM analysis reveals a cell-autonomous role for dTDP-43 in dendritic branching. (A) A wildtype ddaE neuron labeled with GFP by MARCM. (B) A dTDP-43Q367X mutant ddaE neuron labeled with GFP by MARCM. (C) Quantification of dendritic ends of ddaE neurons. The number of neurons examined is indicated in each column. Values are mean $\pm \mathrm{SEM}$. ***P< 0.001 .

moting activity, raising the possibility that loss-offunction mechanism as a contributing factor to the disorder.

\section{Discussion}

The pathological role of TDP-43 was first recognized by its presence in ubiquitin-positive but tau-negative inclusions

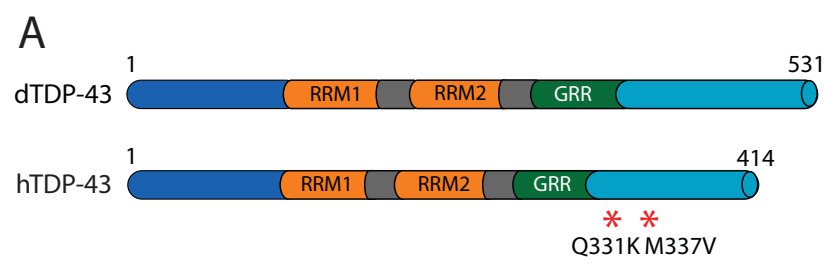

B

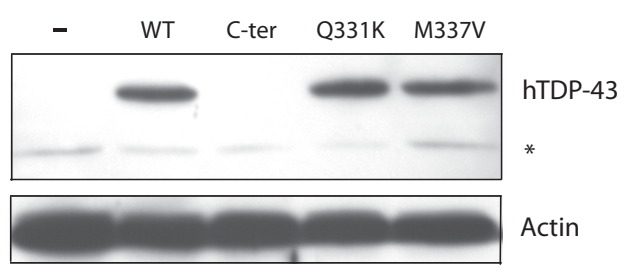

Figure 5

Generation of transgenic flies that express wildtype and mutant hTDP-43. (A) Schematic representations of dTDP-43 and hTDP-43 and the positions of ALS-associated point mutations. RRM: RNA recognition motif. GRR: glycinerich region. (B) Western blot analysis of the levels of wildtype or mutant hTDP-43 expressed in the eye with the GMR-Gal4 driver. The dTDP-43 antibody did not recognize the hTDP-43 C-terminal fragment. The asterisk indicates a nonspecific band. Actin was used as the loading control. in diseased neurons of FTD and ALS patients [10,11]. TDP-43 pathology has two characteristic features. First, TDP-43 is proteolytically processed, and phosphorylated C-terminal fragments of approximately 20-25 kDa are present in the insoluble inclusions [10]. Indeed, ectopic expression of these fragments in cultured cells results in aggregation [33]. Second, TDP-43 is transported from the nucleus, where it predominantly resides in healthy cells. These findings suggest that TDP-43 may contribute to neurodegeneration through both a toxic gain-of-function mechanism and a loss-of-function mechanism. These possibilities are not mutually exclusive. However, the precise roles of TDP-43 in postmitotic neurons remain largely unknown.

Since TDP-43 is highly conserved at the amino acid sequence level from flies to humans, Drosophila offers a powerful model system to examine the endogenous functions of TDP-43. We obtained dTDP-43 null mutant flies and found that dTDP-43 is required for normal viability, consistent with a study published during the preparation of our manuscript [26]. TDP-43 knockout mice have not been reported yet. Considering the high degree of conservation between dTDP-43 and hTDP-43, it is possible that TDP-43 is also essential for normal development in mammals. At the cellular level, multiple lines of evidence from our current study indicate that TDP-43 promotes dendritic branching in postmitotic neurons. This conclusion was based on overexpression studies, RNAi knockdown, and genetic analysis of a dTDP-43 null allele. TDP-43 seems to also regulate axonal structures at the Drosophila neuromuscular junction (NMJ) [26]. These findings indi- 

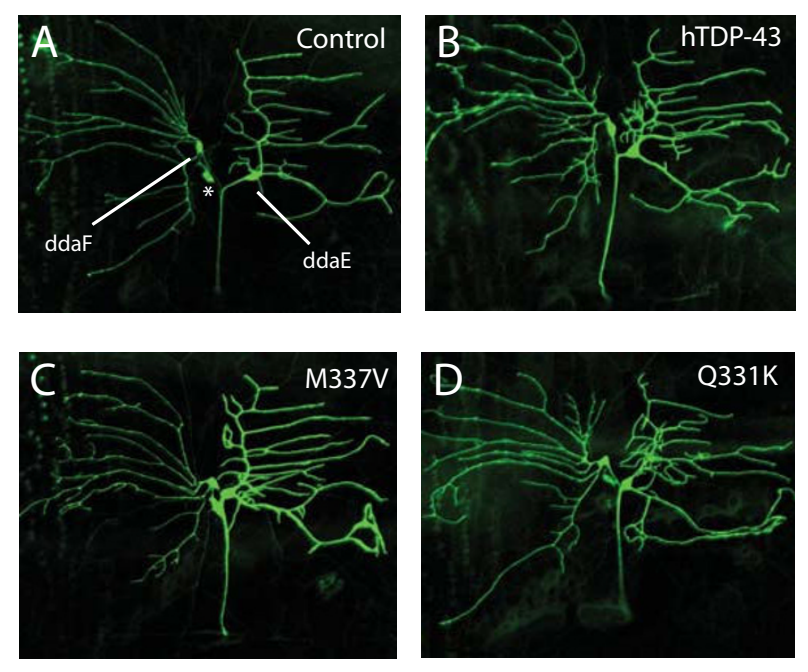

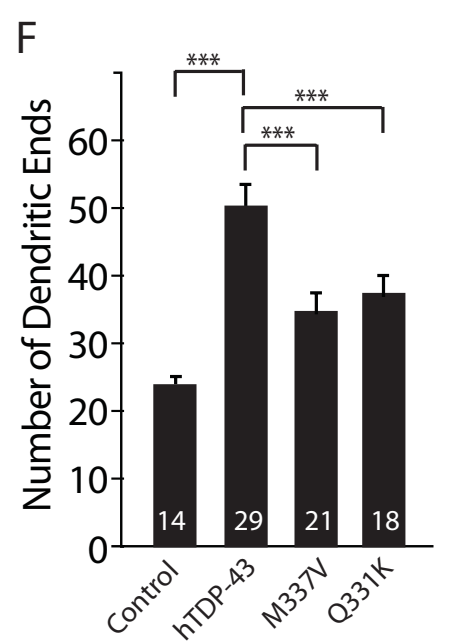

\section{Figure 6}

hTDP-43 promotes dendritic branching in Drosophila neurons and disease-related mutations in $h$ TDP-43 reduce this activity. (A-D) Images of ddaE and ddaF neurons that express mCD8-GFP (A), wildtype hTDP-43 (B), hTDP-43 with the Q33IK mutation (C), and hTDP-43 with the M337V mutation (D). The asterisk indicates another sensory neuron in the cluster that occasionally was weakly labeled with GFP expressed with the Gal422I driver. (E) Quantification of dendritic ends of ddaE neurons. (F) Quantification of dendritic ends of ddaF neurons. The number of neurons examined is indicated in each column. Values are mean \pm SEM. $* * * P<0.001$.

cate an essential role for TDP-43 in neuronal structural integrity.

In many neurodegenerative diseases, defects in synaptic connections are probably one of the earliest alterations preceding neurodegeneration [34]. Recent imaging studies in human brains suggest that specific functional connectivity networks are compromised in specific neurodegenerative conditions [35]. It is conceivable that loss of the normal nuclear function of TDP-43 in specific vulnerable neurons reduces dendritic complexity, which in turn leads to compromised neuronal connectivity in that specific neuronal circuitry. Thus, exclusion of TDP-43 from the nucleus through unknown pathways in diseased neurons may represent a loss-of-function mechanism that may contribute to the pathogenesis of FTD and ALS.

Drosophila is also an excellent model system for studying human disease proteins. We found that hTDP-43 also promotes dendritic branching in Drosophila neurons, indicating a functional conservation. More importantly, two point mutations associated with ALS attenuated the dendrite-promoting activity of hTDP-43. Both are located in a C-terminal region that mediates protein-protein interactions [36]. Thus, these mutations may compromise the normal functions of TDP-43 in neurons. It was reported that these missense mutations might also enhance the for- mation of TDP-43 aggregates [37]. Thus, multiple pathogenic mechanisms may work in concert to promote disease initiation and/or progression.

\section{Conclusion}

Overexpression of dTDP-43 or hTDP-43 in vivo significantly increased dendritic branching in a Drosophila assay system. RNAi knockdown and genetic analysis of a dTDP43 null allele revealed a cell-autonomous role for dTDP43 in promoting dendrite formation. Mutations associated with some forms of ALS reduced the dendrite-promoting activity of hTDP-43, suggesting a loss-of-function pathogenic mechanism. These findings support the notion that loss of normal TDP-43 function may contribute to the pathogenesis of FTD and ALS. The fly model reported here and newly generated relevant reagents will facilitate studies to further elucidate the underlying molecular mechanisms.

\section{Competing interests}

The authors declare that they have no competing interests.

\section{Authors' contributions}

YL and FBG designed the experiments, and YL and JF performed the experiments. YL, JF, and FBG analyzed the data, and wrote the paper. All authors read and approved the final version of the manuscript. 


\section{Additional material}

\section{Additional file 1}

Primers for different transgenic constructs and sequencing primers. Click here for file

[http://www.biomedcentral.com/content/supplementary/17566606-2-30-S1.DOC]

\section{Additional file 2}

Primers for $q R T-P C R$ analysis of dTDP-43 mRNA levels.

Click here for file

[http://www.biomedcentral.com/content/supplementary/17566606-2-30-S2.DOC]

\section{Acknowledgements}

We thank the Vienna Drosophila RNAi Center (VDRC) for providing dTDP43 RNAi lines (38377 and 38379), the Seattle Drosophila TILLING Project for recovering TDP-43 truncation mutant Q367*, and Jin-A Lee for providing the human TDP-43 cDNA construct. We also thank S. Ordway for editorial assistance, S. Mitchell for administrative assistance, and lab members for comments. This work was supported by the NIH (F.-B.G.).

\section{References}

I. Boxer AL, Miller BL: Clinical features of frontotemporal dementia. Alzheimer Dis Assoc Disord 2005, 19:S3-6.

2. Vossel KA, Miller BL: New approaches to the treatment of frontotemporal lobar degeneration. Curr Opin Neurol 2008, 21:708-716.

3. Neumann M, Rademakers R, Roeber S, Baker M, Kretzschmar HA, Mackenzie IR: Frontotemporal lobar degeneration with FUS pathology. Brain 2009 in press.

4. Hong M, Zhukareva V, Vogelsberg-Ragaglia V, Wszolek Z, Reed L, Miller BI, Geschwind DH, Bird TD, McKeel D, Goate A, Morris JC, Wilhelmsen KC, Schellenberg GD, Trojanowski JQ, Lee VM: Mutation-specific functional impairments in distinct tau isoforms of hereditary FTDP-17. Science 1998, 282:1914-1917.

5. Hutton M, Lendon CL, Rizzu P, Baker M, Froelich S, Houlden H, Pickering-Brown $S$, et al.: Association of missense and 5 '-splice-site mutations in tau with the inherited dementia FTDP-I7. Nature 1998, 393:702-705.

6. Watts GD, Wymer J, Kovach MJ, Mehta SG, Mumm S, Darvish D, Pestronk A, Whyte MP, Kimonis VE: Inclusion body myopathy associated with Paget disease of bone and frontotemporal dementia is caused by mutant valosin-containing protein. Nat Genet 2004, 36:377-38I.

7. Skibinski G, Parkinson NJ, Brown JM, Chakrabarti L, Lloyd SL, Hummerich H, Nielsen JE, Hodges JR, Spillantini MG, Thusgaard T, et al.: Mutations in the endosomal ESCRTIII-complex subunit CHMP2B in frontotemporal dementia. Nat Genet 2005, 37:806-808.

8. Baker M, Mackenzie IR, Pickering-Brown SM, Gass J, Rademakers R, Lindholm C, Snowden J, Adamson J, Sadovnick AD, Rollinson S, Cannon A, Dwosh E, Neary D, Melquist S, Richardson A, Dickson D, Berger Z, Eriksen J, Robinson T, Zehr C, Dickey CA, Crook R, McGowan E, Mann D, Boeve B, Feldman H, Hutton M: Mutations in progranulin cause tau-negative frontotemporal dementia linked to chromosome I7. Nature 2006, 442:916-919.

9. Cruts M, Gijselinck I, Zee J van der, Engelborghs S, Wils H, Pirici D, Rademakers R, Vandenberghe R, Dermaut B, Martin JJ, et al.: Null mutations in progranulin cause ubiquitin-positive frontotemporal dementia linked to chromosome I7q2I. Nature 2006, 442:920-924.

10. Neumann M, Sampathu DM, Kwong LK, Truax AC, Micsenyi MC, Chou TT, Bruce J, Schuck T, Grossman M, Clark CM, McCluskey LF, Miller BL, Masliah E, Mackenzie IR, Feldman H, Feiden W, Kretzschmar HA, Trojanowski JQ, Lee VM: Ubiquitinated TDP-43 in frontotemporal lobar degeneration and amyotrophic lateral sclerosis. Science 2006, 3 | 4: | 30- I33.

II. Arai T, Hasegawa M, Akiyama H, Ikeda K, Nonaka T, Mori H, Mann $D$, Tsuchiya $K$, Yoshida M, Hashizume $Y$, Oda T: TDP-43 is a component of ubiquitin-positive tau-negative inclusions in frontotemporal lobar degeneration and amyotrophic lateral sclerosis. Biochem Biophys Res Commun 2006, 35 I:602-6I I.

12. Cairns NJ, Neumann M, Bigio EH, Holm IE, Troost D, Hatanpaa KJ, Foong C, White CL 3rd, Schneider JA, Kretzschmar HA, Carter D, Taylor-Reinwald L, Paulsmeyer K, Strider J, Gitcho M, Goate AM, Morris JC, Mishra M, Kwong LK, Stieber A, Xu Y, Forman MS, Trojanowski JQ, Lee VM, Mackenzie IR: TDP-43 in familial and sporadic frontotemporal lobar degeneration with ubiquitin inclusions. Am J Pathol 2007, I 7 I:227-240.

13. Van Swieten JC, Heutink P: Mutations in progranulin (GRN) within the spectrum of clinical and pathological phenotypes of frontotemporal dementia. Lancet Neurol 2008, 7:965-974.

14. Sreedharan J, Blair IP, Tripathi VB, Hu X, Vance C, Rogelj B, Ackerley S, Durnall JC, Williams KL, Buratti E, Baralle F, de Belleroche J, Mitchell JD, Leigh PN, Al-Chalabi A, Miller CC, Nicholson G, Shaw CE: TDP-43 mutations in familial and sporadic amyotrophic lateral sclerosis. Science 2008, 3 I 9: I668-I672.

15. Kabashi E, Valdmanis PN, Dion P, Spiegelman D, McConkey BJ, Velde $C$ Vande, Bouchard JP, Lacomblez L, Pochigaeva K, Salachas F, Pradat PF, Camu W, Meininger V, Dupre N, Rouleau GA: TARDBP mutations in individuals with sporadic and familial amyotrophic lateral sclerosis. Nat Genet 2008, 40:572-574.

16. Rutherford NJ, Zhang YJ, Baker M, Gass JM, Finch NA, Xu YF, Stewart H, Kelley BJ, Kuntz K, Crook RJ, Sreedharan J, Vance C, Sorenson E, Lippa C, Bigio EH, Geschwind DH, Knopman DS, Mitsumoto H, Petersen RC, Cashman NR, Hutton M, Shaw CE, Boylan KB, Boeve B, Graff-Radford NR, Wszolek ZK, Caselli RJ, Dickson DW, Mackenzie IR, Petrucelli L, Rademakers R: Novel mutations in TARDBP (TDP-43) in patients with familial amyotrophic lateral sclerosis. PLoS Genet 2008, 4:el000I93.

17. Geser F, Martinez-Lage M, Robinson J, Uryu K, Neumann M, Brandmeir NJ, Xie SX, Kwong LK, Elman L, McCluskey L, Clark CM, Malunda J, Miller BL, Zimmerman EA, Qian J, Van Deerlin V, Grossman M, Lee VM, Trojanowski JQ: Clinical and pathological continuum of multisystem TDP-43 proteinopathies. Arch Neurol 2009, 66:180-189.

18. Moisse K, Volkening K, Leystra-Lantz C, Welch I, Hill T, Strong MJ: Divergent patterns of cytosolic TDP-43 and neuronal progranulin expression following axotomy: implications for TDP-43 in the physiological response to neuronal injury. Brain Res 2009, I 249:202-2II.

19. Wang IF, Wu LS, Shen CK: TDP-43: an emerging new player in neurodegenerative diseases. Trends Mol Med 2008, 3 I 2:479-485.

20. Casafont I, Bengoechea R, Tapia O, Berciano MT, Lafarga M: TDP-43 localizes in mRNA transcription and processing sites in mammalian neurons. J Struct Biol 2009, I 67:235-24I.

21. Ou SH, Wu F, Harrich D, Garcia-Martinez LF, Gaynor RB: Cloning and characterization of a novel cellular protein, TDP-43, that binds to human immunodeficiency virus type I TAR DNA sequence motifs. J Virol 1995, 69:3584-3596.

22. Buratti E, Dörk T, Zuccato E, Pagani F, Romano M, Baralle FE: Nuclear factor TDP-43 and SR proteins promote in vitro and in vivo CFTR exon 9 skipping. EMBO J 200I, 20: I 774- I784.

23. Ayala YM, Pantano S, D'Ambrogio A, Buratti E, Brindisi A, Marchetti C, Romano M, Baralle FE: Human, Drosophila, and C. elegans TDP43: nucleic acid binding properties and splicing regulatory function. J Mol Biol 2005, 348:575-588.

24. Wang IF, Wu LS, Chang HY, Shen CK: TDP-43, the signature protein of FTLD-U, is a neuronal activity-responsive factor. J Neurochem 2008, I05:797-806.

25. Gregory RI, Yan KP, Amuthan G, Chendrimada T, Doratotaj B, Cooch N, Shiekhattar R: The Microprocessor complex mediates the genesis of microRNAs. Nature 2004, 432:235-240.

26. Feiguin F, Godena VK, Romano G, D'Ambrogio A, Klima R, Baralle FE: Depletion of TDP-43 affects Drosophila motoneurons terminal synapsis and locomotive behavior. FEBS Lett 2009, 583: I586- I592.

27. Parrish JZ, Kim MD, Jan LY, Jan YN: Genome-wide analyses identify transcription factors required for proper morphogenesis of Drosophila sensory neuron dendrites. Genes Dev 2006, 20:820-835. 
28. Li W, Wang F, Menut L, Gao F-B: BTB/POZ-zinc finger protein Abrupt regulates dendritic branching in a neuronal subtypespecific and dosage-dependent manner. Neuron 2004, 43:823-834.

29. Parrish JZ, Emoto K, Kim MD, Jan YN: Mechanisms that regulate establishment, maintenance, and remodeling of dendritic fields. Annu Rev Neurosci 2007, 30:399-423.

30. Zoghbi HY: Postnatal neurodevelopmental disorders: meeting at the synapse? Science 2003, 302:826-830.

31. Gao FB: Molecular and cellular mechanisms of dendritic morphogenesis. Curr Opin Neurobiol 2007, 1 7:525-532.

32. Lee T, Luo L: Mosaic analysis with a repressible cell marker for studies of gene function in neuronal morphogenesis. Neuron 1999, 22:45|-46|.

33. Igaz LM, Kwong LK, Chen-Plotkin A, Winton MJ, Unger TL, Xu Y, Neumann M, Trojanowski JQ, Lee VM: Expression of TDP-43 Cterminal fragments in vitro recapitulates pathological features of TDP-43 proteinopathies. J Biol Chem 2009, 284:8516-8524.

34. Haass C, Selkoe DJ: Soluble protein oligomers in neurodegeneration: lessons from the Alzheimer's amyloid beta-peptide. Nat Rev Mol Cell Biol 2007, 8:10I-12.

35. Seeley WW, Crawford RK, Zhou J, Miller BL, Greicius MD: Neurodegenerative diseases target large-scale human brain networks. Neuron 2009, 62:42-52.

36. D'Ambrogio A, Buratti E, Stuani C, Guarnaccia C, Romano M, Ayala YM, Baralle FE: Functional mapping of the interaction between TDP-43 and hnRNP A2 in vivo. Nuc Acids Res 2009, 37:4I| 6-6I26

37. Johnson BS, Snead D, Lee JJ, McCaffery JM, Shorter I J, Gitler AD: TDP-43 is intrinsically aggregation-prone, and amyotrophic lateral sclerosis-linked mutations accelerate aggregation and increase toxicity. J Bio Chem 2009, 284:20329-20339.

Publish with Bio Med Central and every scientist can read your work free of charge

"BioMed Central will be the most significant development for disseminating the results of biomedical research in our lifetime. "

Sir Paul Nurse, Cancer Research UK

Your research papers will be:

- available free of charge to the entire biomedical community

- peer reviewed and published immediately upon acceptance

- cited in PubMed and archived on PubMed Central

- yours - you keep the copyright

Submit your manuscript here:

http://www.biomedcentral.com/info/publishing_adv.asp
BiolMedcentral 